\author{
Military Technical College \\ Kobry El-Kobbah, \\ Cairo, Egypt.
}

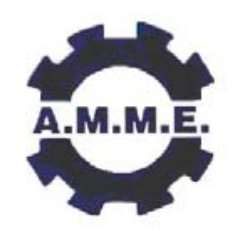
$13^{\text {th }}$ International Conference on Applied Mechanics and Mechanical Engineering.

\title{
FRACTURE BEHAVIOR OF THE POLYMETHYL METHACRYLATE WITH TWO DIFFERENT CURING PROCESSES
}

\author{
EL-ASSAL* A.M., AL-DOSARY** S., SHEHATA ${ }^{+}$M.M. and BASALAH** A.A.
}

\begin{abstract}
The usage of Polymers in different fields is enormous and crucial. Polymethyl Methacrylate (PMMA) is one of the earliest widely used polymers, and well known around the world by a variety of trade names; Lucite, Oroglas, Perspex, Plexiglas and acrylic resin which may vary from country to country. This material is one of the hardest polymers, rigid and good weather resistance.
\end{abstract}

The usage of PMMA is widely spread in the medical technologies which reflected from a good degree of compatibility with human tissue, and can be used for replacement of intraocular lenses in the eye when the original lens has been removed in the treatment of cataracts. In orthopaedics, PMMA bone cement is used to affix implants and to remodel lost bone caused by traffic accident and war injures. In cosmetic surgery, tiny PMMA microspheres suspended in some biological fluid are injected under the skin to reduce wrinkles or scars permanently.

Parts made of PMMA have high mechanical strength and good dimensional stability. Other reported properties include a high Young's modulus and good hardness with low elongation at break. Therefore, PMMA was used extensively as aircraft windshields for many aircraft (hitting a bird at $600 \mathrm{mph}$ is dangerous to aircraft as it is deadly for birds). On the other side, typical working loads during Polymers service are the loads leading to fracture. Even though this kind of loading resistance in PMMA is important, there is a deficiency in the literature in this area. Accordingly, covering this area constitutes very important potential for research and study.

Therefore, the purpose of this research is to investigate the fracture behavior of PMMA. Two methods of preparing the specimens (method of cure) will be taken into consideration. As a result of this research, more accurate data about fracture and mechanical properties about this widely used material in dental applications are becoming available for dentists. Tensile, compression and fracture tests were carried out in this study. The results showed that a slight improve in the tensile strength of the long curing process specimens compared with short curing specimens. However, the compressive strength of the short curing is better than long curing specimens. The fracture test results showed that the fracture toughness of the short curing specimens is higher than that of the long curing specimens.

* Benha University, ${ }^{* *}$ King Abdulaziz University and + Tanta University. 


\section{INTRODUCTION AND REVIEW}

New materials and methods for denture resin processing are proposed from time to time with the main purpose of finding a technique to manufacture high quality dentures in less time than is spent using traditional processing techniques. Poly Methyl Methacrylate (PMMA) polymers were introduced as denture base materials in 1937 opened up new prospects for the manufacture of totally and partially removable dentures. The acrylic Resin (PMMA) was so well received by the dental profession by 1946[1]. The vast majority of dentures base made today are fabricated from heat-cured PMMA.

Despite its popularity in satisfying aesthetic demands whereby, with an appropriate degree of clinical expertise and with the careful selection and arrangement of artificial acrylic teeth, it is possible to produce a prosthesis which defies detection but it is still far from ideal in fulfilling the mechanical requirements of prosthesis. The impact and fatigue strength of PMMA are not entirely satisfactory and this is reflected by the expenditure on a large number of denture repairs annually. Presently the dental Practice Board spends approximately $£ 18$ million annually to repair about 1.2 million dentures (Dental Practice Board, 1997) [2]. There is a great scientific and technological interest in the study and understanding of the fracture behavior.

Vallittu et al [3], Bartoloni et al [4], and Lung \& Darvell [5,6] were concerned with the residual monomer content and its effect on the mechanical properties of the material as a plasticizer and as tissue irritant. They tried to identify the optimum processing conditions which assure the minimum residual monomer to the point where both biological and mechanical effects are negligible.

Craig \& Power [1] recommended two processing method to lessen the residual monomer and to avoid the porous occurrence as follow:

- Cure the PMMA in a constant temperature water bath at $74{ }^{\circ} \mathrm{C}$ for 8 hours or longer.

- Cure the PMMA in a constant temperature water bath at $74{ }^{\circ} \mathrm{C}$ for 1.5 hours and then increase the temperature of the water bath to boiling for an additional hour.

Vallittu, [7], Teraoka et al [8], Shimizu et al [9], Hiroyuki et al [10] have investigated the effect of various types of metal wires and plates as reinforcing materials or technique on the transverse strength of the PMMA-metal composite. In clinical use, adaptability of the dentures should take precedence over the increase in transverse strength of the dentures because of the use of reinforcing wire. Therefore, the reinforcing of the denture with metal wire is not yet a proper solution for this problem [8].

Polymer-fiber composites are reputed to have excellent mechanical properties. Therefore, polymer-fiber composites based on PMMA resin and either organic or inorganic fibers have been tested as suitable materials for prosthodontics by PK [11], Vallittu PK [12], Shehata et al [13], Foo et al [14], Rantala et al [15], and Kanie et al [16]. The main use for these materials is for reinforcing the polymer resin of removable partial and complete dentures and provisional restorations in fixed prosthodontics.

Reinforcing the PMMA with other modifiers is investigated by many researchers. ElSegaii et al [17] investigated a new attempt to improve some of the properties of the 
acrylic resin by the addition of various ratios of two different organometallic (OM) compounds (with different metals and different organic skeletons). Lassila \& Vallittu [18] determined flexural properties, water sorption, solubility and release of residual compounds of a new paste type denture base polymer Alldent Sinomer. Zappini et al [4], Jagger et al [19], and Phoenix et al [20] were compared between the plain PMMA and the enhanced PMMA material with a modifier which is a butadiene-styrene rubber forms high-impact strength material.

The purpose of this research is to investigate certain mechanical properties and the fracture behavior of PMMA using two different curing methods.

\section{MATERIAL AND METHODS}

\section{Specimens Preparation and Testing Scheme}

The scientific name of the material being used is "PolyMethyl Methacrylate" which is a polymer, shorthanded by PMMA having chemical structure units derived from methyle methacrylate as indicated in Fig. (1).

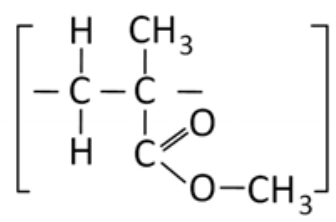

Fig.(1): Diagrammatic illustration of the PMMA chemical structure.

The tensile test specimens were processed according to American Society for Testing and Materials (ASTM D638). Each specimen had the dimensions of $41 \mathrm{~mm}$ (gauge length) $\times 6 \mathrm{~mm}$ (diameter). In the other side, the compression test specimens were fabricated according to American Society for Testing and Materials (ASTM E9). The fracture test specimens were prepared according to American Society for Testing and Materials (ASTM E399).

\section{Mold preparation and packing of the acrylic resin}

The specimens were produced in moulds made by investing aluminum patterns of the required size into dental stone. The stone mix was prepared according to the manufacturer's instructions and vibrated to expel out air from it then it was poured into the lower half of the flask. Because the resin should be carefully protected from the dental stone surface surrounding the mold space, so sodium alginate was applied as a separating medium to the mold space providing a thin and uniform coating.

Heat cured PMMA was used for fabricating the test specimens. The proper monomer to polymer ratio as recommended by manufacturer $(23.4 \mathrm{~g}$ powder to $10 \mathrm{ml}$ liquid) was used, and was thoroughly mixed and allowed to reach the dough stage in air-tight mixing Jar. The dough was packed into the mold space and the two halves were closed under pressure which was maintained until the specimens have been processed. All sets of specimens were subjected to the same curing cycle. The flask was submersed 
in tap water then the desired temperature, $73{ }^{\circ} \mathrm{C}$, was set on using a temperature controller which was with a timer that was set to nine hours for long curing cycle, and for two hours followed by one hour on the boiling temperature for short curing cycle.

After the curing cycle was finished, the mould was raised from the water path and put it on the bench to cool off for half an hour. The mould was deflasked and the specimens were derived from the mould. The excess of the casting process was removed and specimens were finished with sand papers of: 120, 220, 400, 600 and 800 Grit. After the finishing process was implemented, specimens were stored in the distilled water until reached the saturation (check Fig. 3) after 14 weeks. Finally, the specimens were ready for mechanical tests.

\section{Mechanical Testing}

\section{Tensile and compressive tests}

Tensile and compressive tests are the most common tests used for determining the essential mechanical properties information that is usually used during the stress analysis or the design calculation. The tensile or compressive test gives a measure of the Young's modulus of the material as well as the strength and yield point. Ductility and toughness can be easily measured through such tests. Tensile and compressive test data were averaged for testing results over four specimens for each case.

\section{Fracture testing}

In the construction of such systems it is impossible to completely avoid the presence of flaws such as cracks, micro voids, and mix-irregularities. Fracture test is costly. It needs a well trained person to design specimens growing a crack in the specimens. As a result, not many laboratories are equipped to conduct fracture test. Even after having so much progress on analytical side, a designer still finds himself ill-equipped in selecting a material in the absence of an extensive data bank. This experiment is designed to illustrate how strength in the presence of cracks - termed Fracture Toughness - is characterized and measured.

The form of the fracture test specimens after the curing process were cubical, then the specimens were machined by milling machine to open the notch and using the razor blade to making the initial crack growth. Two types of specimens were produced from that process which used in the fracture test is compact tension specimen. The fracture Toughness in units of (MPa. $\mathrm{m}^{1 / 2}$ ) was calculated from the following expression:

$$
K_{Q}=\left(\frac{P_{Q}}{B W^{\frac{1}{2}}}\right) \cdot f\left(\frac{a}{W}\right)
$$

where:

$$
f\left(\frac{a}{W}\right)=\frac{\left(2+\frac{a}{W}\right)\left[0.886+4.64\left(\frac{a}{W}\right)-13.32\left(\frac{a}{W}\right)^{2}+14.72\left(\frac{a}{W}\right)^{3}-5.6\left(\frac{a}{W}\right)^{4}\right]}{\left(1-\frac{a}{W}\right)^{\frac{3}{2}}}
$$


where $P_{Q}$ is the load in $K N, B$ is the specimen thickness in $(\mathrm{cm}), W$ is the Specimen width measured to hole centers $w(\mathrm{~cm})$, and $a$ is the crack length (measured from three location along the line of fracture and take the average $\left.a_{i}\right)(\mathrm{cm})$.

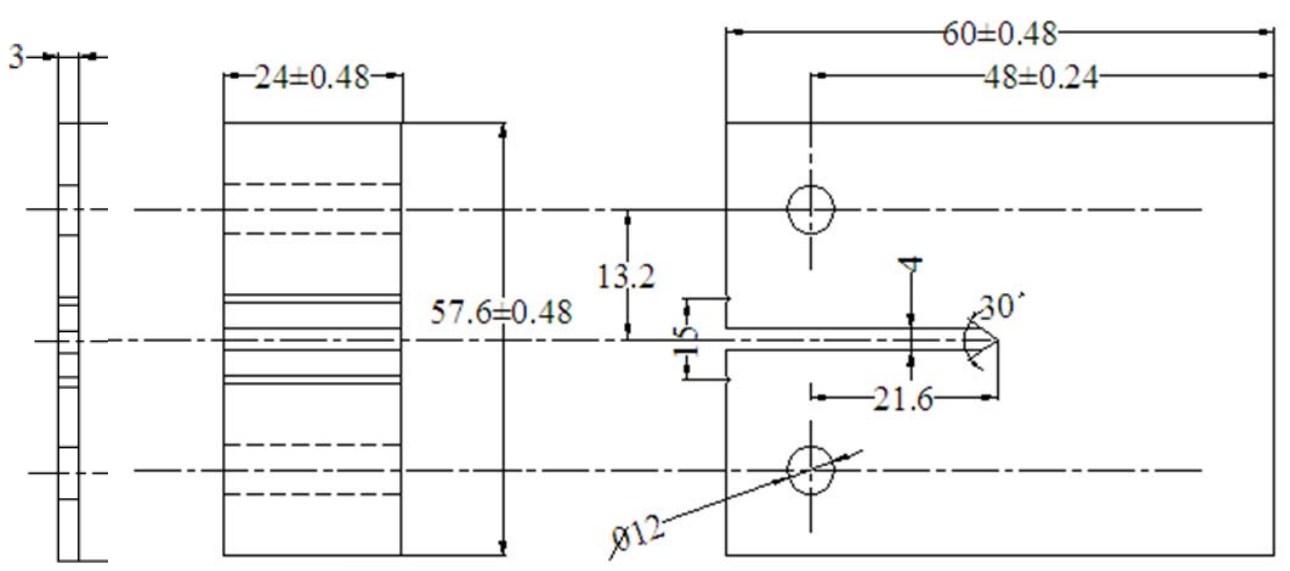

(a)

(b)

Fig.(2): Compact tension specimens used for fracture toughness, all dimensions in mm.. (a) Plane stress, (b) Plane strain

\section{RESULTS AND DISCUSION}

Figure 3 presents the saturation of water absorption by the PMMA material. These results are the averaged data of three different specimens. This phenomenon is important to be characterized since the service of this material is usually associated with soaking in water similar solutions. As shown in the figure, saturation has almost occurred at 2000 to 2500 hours (12 to 14 weeks). The experimental data of the water absorption are modeled to best fit the following equation

where:

$$
w=A \ln (t)-B
$$

$\begin{array}{ll}w & \text { water absorption in percentage of the specimen weight } \\ t & \text { soaking time elapsed in hours } \\ A, B & \text { material constants }\end{array}$

When used in dental applications, this material is usually subjected to frequent applications of combinations of tensile and compressive stresses. The current study takes into consideration two curing cycles applied in dental laboratories on a popular denture base resin. The mechanical properties and fracture behavior for this specific material has not been previously studied or reported in the literature. Therefore many tests were carried out to obtain these properties and to compare between the behaviors of specimens prepared according to the two used curing cycles.

According to the tensile results (the dotted lines in Fig. 5), almost no difference was noticed neither for long cure nor short cure specimens. Both developed similar tensile strength and total elongation at failure (about $4 \%$ total strain). Compressive results, 


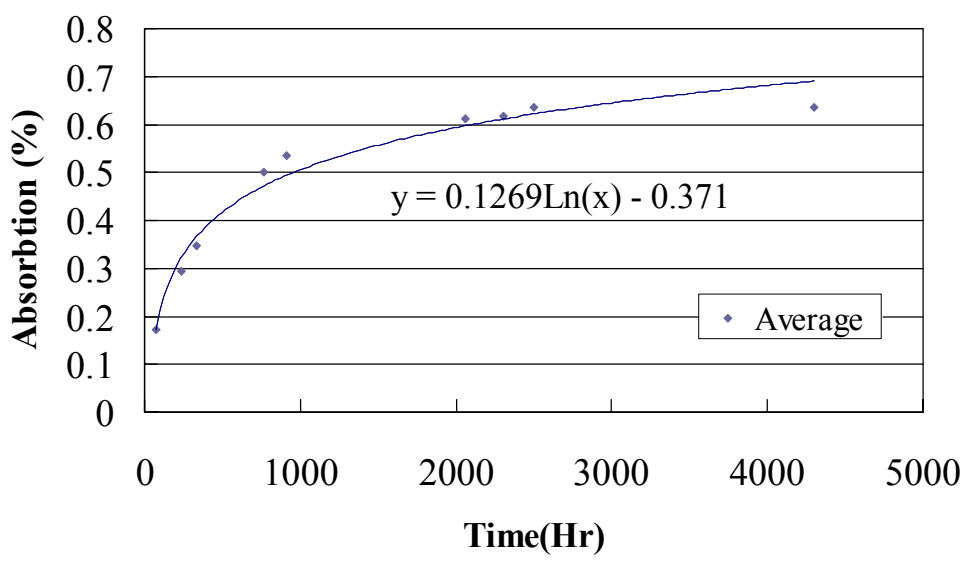

Fig.(3): Water absorption of the PMMA chemical structure.

however, showed a slightly different behavior. Short cure specimens developed little higher strength when compared with long cured ones. This may be due to the higher temperature scheme that was followed, that may be contributed to a better cross linking during the thermo setting process which was reflected on the strength of the prepared specimens. Another point of interest, all specimens that were tested in compression did not fail up to $14 \%$ of total strain. So, both the strength and determination results of tensile and compression specimens are slightly different. First of all, ductility in tension is not similar to compression as the total deformation in compression reaches more than three times as much as it is in tension. Also, the inelastic part of the stress strain behavior is not exactly similar in tension and compression. In addition, strength in compression is obviously higher than it is in tension (similar to concrete). As a simple outcome that can be derived from this is that the toughness during tension is much less than it is in compression. Accordingly, this to a great extent is helpful in determining the nature of loadings for components manufactured from such material.

Examination of fracture surface of tensile specimens showed that both typical brittle and ductile failure zones existed. Fig.2 shows these zones on a fracture surface of a tested tensile specimen. Visual examination of the fracture surface showed that there are two zones representing two types of fracture as follow: Zone 1 (Fig.4) represents brittle fracture (cleavage with shines surfaces) while Zone 2 which tends to represent ductile fracture as the surface appears with dimples. Also, it is obvious that no reduction in cross section was noticed in the fracture zone (necking).

The comparison between the two curing processes was represented in the Fig.5. TABLE.1 shows the properties of PMMA processed by two curing cycles have almost no change in tensile and yield strength as displayed by long and short curing specimens. Also, there was no obvious change in Young's modulus due to the change of curing cycle. In compression test results, as mentioned previously the compressive strength of the short curing specimens is higher than the long curing specimens (about $6 \%$ ), and in the both curing process the specimens were not shattered during the test. The difference due to curing processes in the case of compressive load was shown in the Fig.3. Qualitatively, long and short cured specimens developed similar behavior under compressive loadings. Summary of compressive tests are in Table 1. 


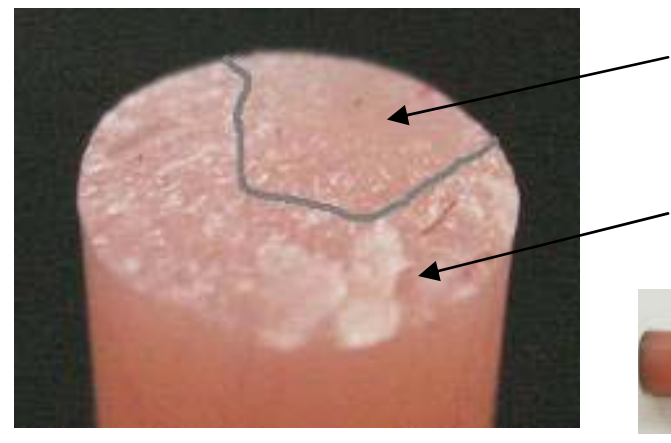

Zone 1

Zone 2

Fig. 4 Tensile fracture of the PMMA specimen.

Table.1 Mechanical Properties of PMMA processed by two curing cycle.

\begin{tabular}{|c|c|c|c|c|}
\hline \multirow{2}{*}{ Tension } & $\begin{array}{c}\text { Cure } \\
\text { Cycle }\end{array}$ & $\begin{array}{c}\text { Yield strength } \\
\text { (Proof } \\
\text { stress)(MPa) }\end{array}$ & $\begin{array}{c}\text { Tensile } \\
\text { strength } \\
\text { (MPa) }\end{array}$ & $\begin{array}{c}\text { Young's } \\
\text { modulus } \\
\text { (GPa) }\end{array}$ \\
\cline { 2 - 5 } & $\begin{array}{c}\text { Short Curing } \\
\text { cycle }\end{array}$ & 26.5 & 59 & 2.095 \\
\hline \multirow{2}{*}{ Compression } & $\begin{array}{c}\text { Long Curing cycle } \\
\text { Short Curing } \\
\text { cycle }\end{array}$ & 27 & 60.5 & 2.125 \\
\cline { 2 - 5 } & Long Curing cycle & 41 & 80 & 2.15 \\
\hline
\end{tabular}

The fracture toughness as determined by stress intensity factors as indicated in the huge literature dealing with fracture. Stress intensity factors are very important factor in determining the fracture behavior of materials. Standard compact tension test specimens (Fig. 2) were used in such tests. Tests used in the present study are meant to complete the literature data of PMMA in regard of mechanical properties. Not only the peak load (from which $\mathrm{K}_{l}$ is calculated) but also the shape of the load displacement curves during crack propagation may be also important for the assessment of a material. Obtaining the $\mathrm{K}_{\mathrm{l}}$ will cover two main aspects of the material. The first parameter measures the sensitivity of materials to the presence of sharp notches (crack initiation); while the second indicates how well the material can withstand the propagation of the crack.

During the fracture toughness experiments of plane strain specimens, the material became unstable after reaching the peak load, with rapid acceleration of crack speed thereafter. The material exhibited a smooth shiny fracture surface in short curing specimens, however, long curing specimens exhibited more ductile fracture with a small amount of permanent deformation and crazing, which produced an irregular fracture surface as shown in Fig.6. The results of the load deflection curve, Fig.7, showed that 


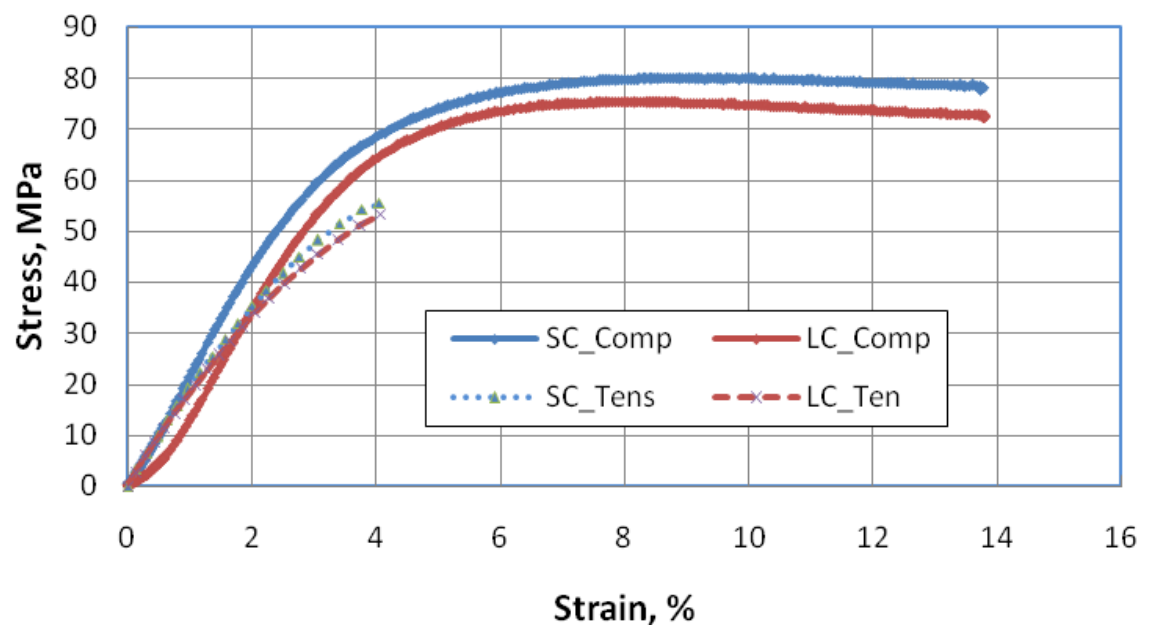

Fig.5 A comparison of the tension and compression data for two curing cycles of processing the PMMA.

the fracture toughness values of the short curing specimens were significantly higher than those of the long curing specimens. Scattering of fracture results is not high especially for short curing specimens. The results in Fig. 7 were used with the help of equation (1) to calculate the stress intensity factor, $\mathrm{K}_{\mathrm{IC}}$, for the PMMA material. This constant can be of great help in predicting service life of components made from this material. Stress intensity factors of the two differently cured materials are presented in Fig. 8. Long cured specimens displayed noticeably higher stress intensity factors when compared with short cure specimens. Stress intensity, $\mathrm{K}_{\mathrm{IC}}$, of the plane stress specimens (as shown in Fig. 8) is clearly less than it is in plane strain, which agrees with the published data for other materials.

\section{CONCLUSIONS}

This study presented a thorough investigation for short and long cured processes of a commonly used denture base polymer, PMMA. Within the limitations of the conducted study, the following conclusions can be highlighted:

- A water absorption curve for PMMA material was determined experimentally and an approximate empirical model was developed. Saturation was found to happen after about 2000 (12 weeks) hours.

- Compressive strength of the PMMA material was obviously higher than it was for tensile. Total elongation before failure was much higher in case of compression when compared with tension.

- Fracture properties (Indicated by stress intensity factor), was determined for the PMMA material. The stress intensity was determined for two differently cured materials.

- Short curing process showed a slight improvement in the fracture properties when compared with long curing process, this leads to a more effective way of producing denture base in the labs since short cure consumes less time in preparation. 

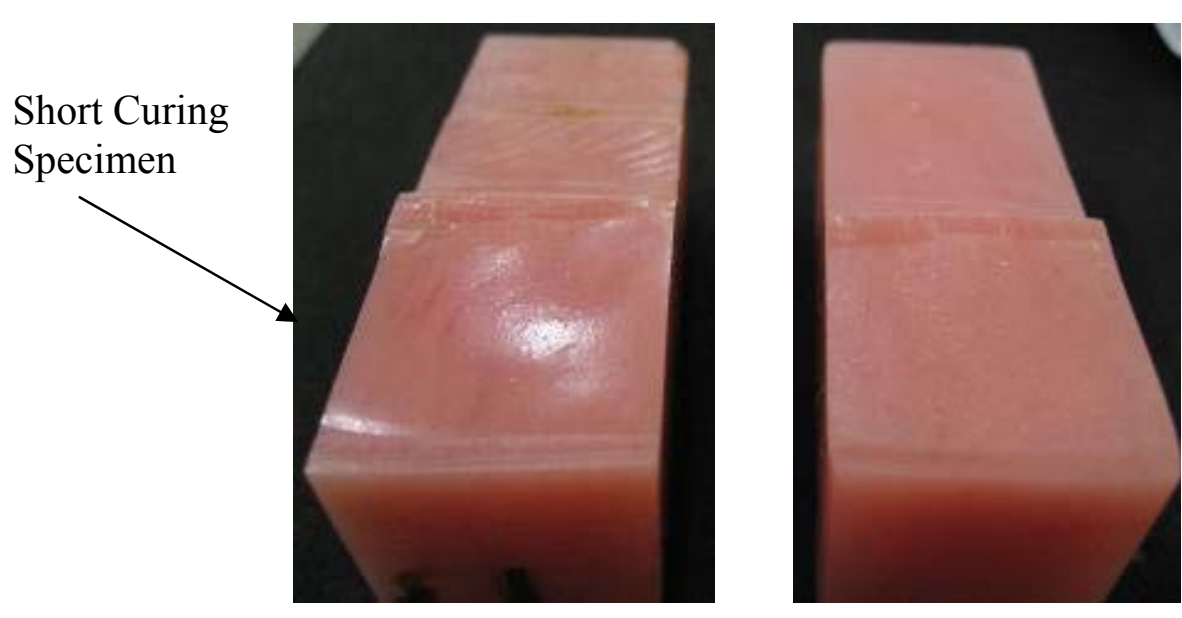

Long Curing

Specimen
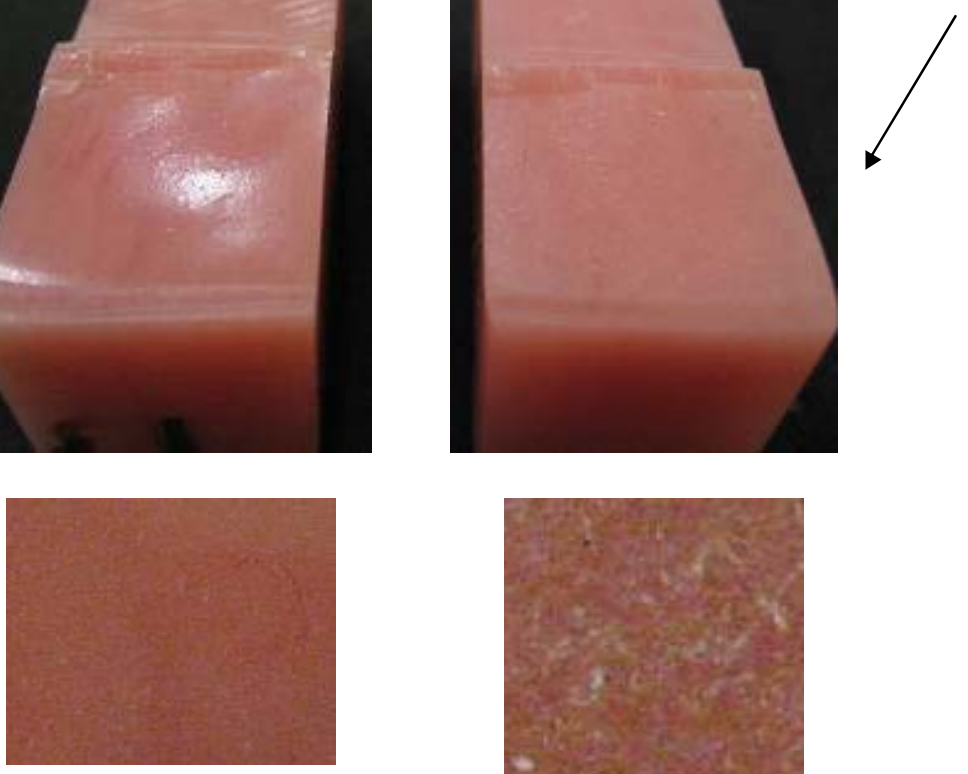

Fig. 6 Difference between fracture surfaces of the short and long curing of the fracture toughness specimens

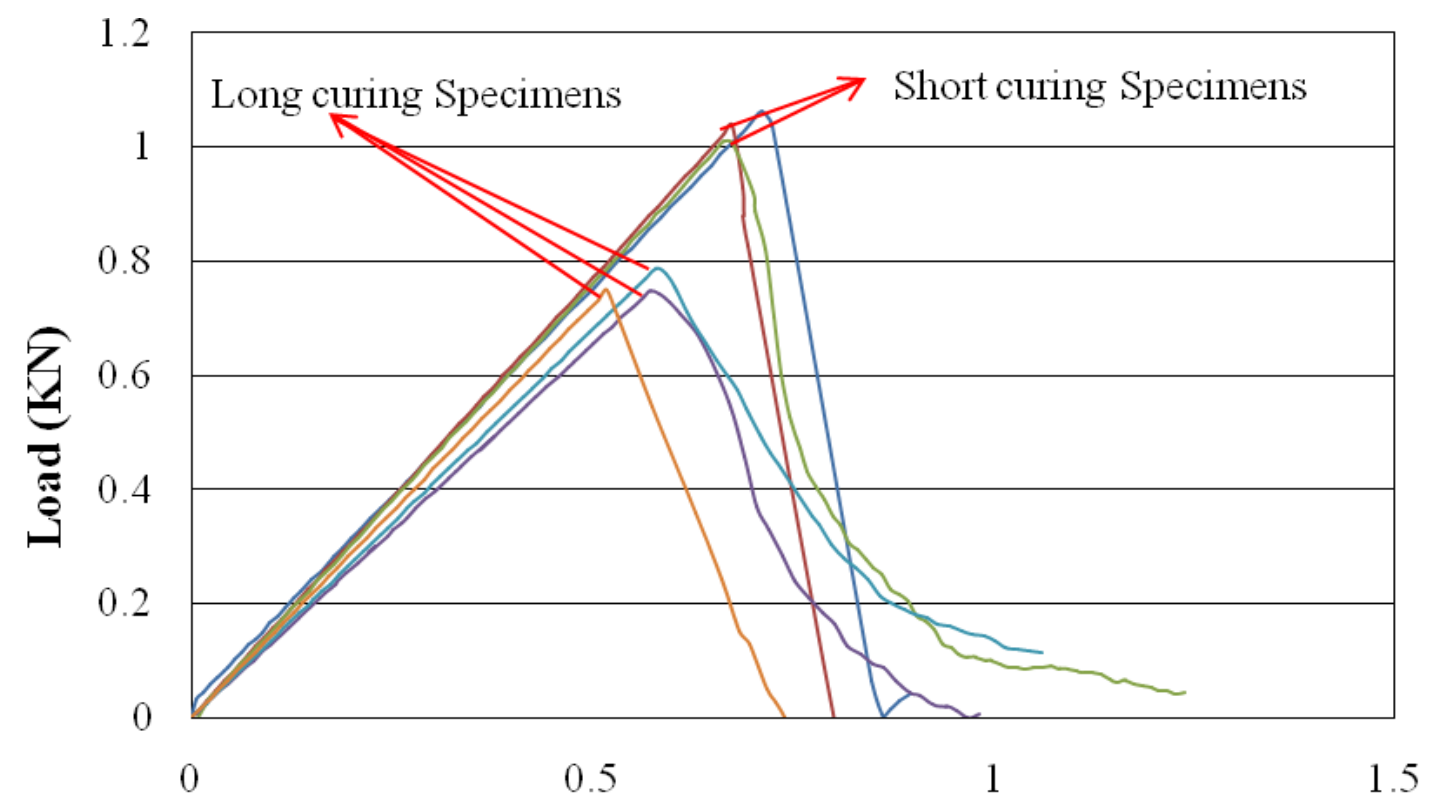

Displacement $(\mathbf{m m})$

Fig.7 load deflection curve of the fracture test. 


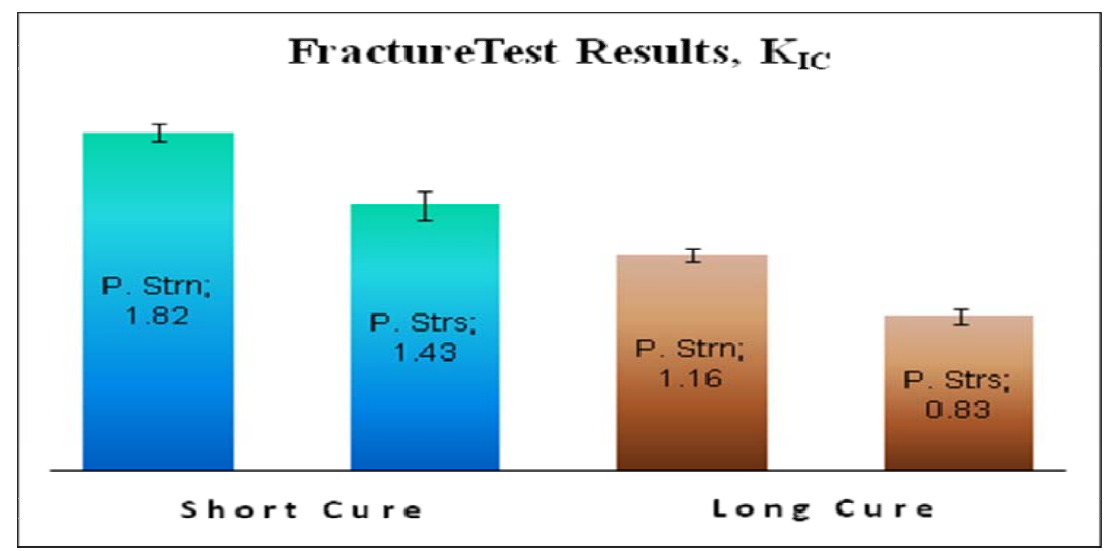

Fig. 8 Stress intensity factors of two curing cycles for plane stress and plane strain specimens in MPa $\mathrm{m}^{1 / 2}$.

\section{REFERNENCES}

[1] Craig, R.G \& Powers, J.M. "Restorative dental materials, $11^{\text {th }}$ edition. St. Louis: CV Mosby. (2002)

[2] Dental Practice Board "Dental Practice Board Annual Report,. Eastbourne, U.K. (1997)

[3] Vallittu, P.K., Ruyter, I.E. \& Buykuilmaz, S. "Effect of polymerization temperature and time on the residual monomer content of denture base polymers,. European Journal Of Oral Sciences, vol.106, pp.588-593. (1998)

[4] Bartoloni, J.A., Murchison, D.F., Wofford, D.T. \& Sarkar, N.K. "Degree of conversion in denture base materials for varied polymerization techniques,. J Oral Rehabil, vol.27, pp.488-93. (2000)

[5] Lung, C.Y.K. \& Darvell, B.W. "Methyl methacrylate monomer-polymer equilibrium in solid polymer,. Journal of dental, 894. (2005a)

[6] Lung, C.Y.K. \& Darvell, B.W. "Minimization of the inevitable residual monomer in denture base acrylic. Journal of Dental Materials, vol.21, pp.1119-1128. (2005b)

[7] Vallittu, P.K. "A Review of Methods Used to Reinforce Polymethyl Methacrylate Resin,. Journal Of Prosthodontics,vol.4, No. 3,pp.183-187. (1995)

[8] Teraoka, F., Nakagawa, M. \& Takahashi, J. "Adaptation of acrylic dentures reinforced with metal wire,. Journal of Oral Rehabilitation, vol.28, pp.937-942. (2001)

[9] Shimizu, H., Ikeda, T., Wakabayashi, N. \& Ohyama, T. "Effect of metal strengthener length on stress distribution in acrylic denture bases: a finite element study,. Journal of Oral Rehabilitation, vol.31, pp.879-883. (2004)

[10] Hiroyuki, M., Shiro, S., Hisanori K., Yoshito, M. \& Takuo, T. "Flexural Strengths of Denture Base Resin Repaired with Autopolymerizing Resin and Reinforcements After Thermocycle Stressing,. Journal of Prosthodont, vol.14, pp.12-18. (2005)

[11] Vallittu, P.K. "A Review of Fiber-Reinforced Denture Base Resins,. Journal Of Prosthodontics, vol. 5, No 4, pp.270-276. (1996) 
[12] Vallittu, P.K. "Flexural properties of acrylic resin polymers reinforced with unidirectional and woven glass fibers, . Journal of Prosthodent;81, 318-326. (1999)

[13] Shehata, M. M., El-Gendy, A. A. \& El-Assal, A. M. "Laminate Polymer Composite: A comparative Laboratory Study,. Cairo dental journal, vol.14, No 1, pp.49-53. (1998)

[14] Foo, H. S., Lindquist, T. J., Aquilino, S. A., Schneider, R. L., Williamson, D. L., \& oyer, D. B. "Effect of Polyaramid Fiber Reinforcement on the Strength of 3 Denture Base Polymethyl Methacrylate Resins,. Journal of Prosthodontics,vol.10, No.3, pp148-153. (2001)

[15] Rantala, L. I., Lastumaki,T.M., Peltomaki, T.\& Vallittu, P. K. "Fatigue resistance of removable orthodontic appliance reinforced with glass fibre weave,. Journal of Oral Rehabilitation, vol.30, pp.501-506. (2003)

[16] Kanie, T., Arikawa, H., Fujii, K. \& Ban, S. Flexural properties of denture base polymers reinforced with a glass cloth-urethane polymer composite.. Journal of dental materials, vol.20, pp.709-716. (2004)

[17] El-Segaii, A. A., El-Hiti, G. A., El-Assal, A. M. \& Sayyah, S. M. “Two Organometallic Compounds For Improving The Properties Of Acrylic Resin,. Cairo dental journal, vol.13, pp.43-49. (1997)

[18] Lassila, L. V. J. \& Vallittu, P. K."Denture base polymer Alldent Sinomer: mechanical properties, water sorption and release of residual compounds,. Journal of Oral Rehabilitation, vol.28, pp.607-613. (2001)

[19] Jagger, D.C., Jagger, R.G., Allen, S.M \& Harrison, A. "An investigation into the transverse and impact strength of 'high strength' denture base acrylic resins,. Journal of Oral Rehabilitation, vol.29, pp.263-267. (2002)

[20] Phoenix, R.D., Mansueto, M.A., Ackerman, N.A. \& Jones, R.E. "Evaluation of Mechanical and Thermal Properties of Commonly Used Denture Base Resins,. Journal of Prosthodontics, vol.13, pp.17-27. (2004)

[21] American Standard Test Methods ASTM E9.

[22] American Standard Test Methods ASTM D638.

[23] American Standard Test Methods ASTM E399. 